\title{
Incorporation of Actuarial Sciences education course in academic domain: its scope, necessity, expected efficacy and contribution, therein development proposal for Bangladesh
}

\author{
Mahfuz Ibn Mannan \\ Department of Natural Sciences, University of Information Technology \& Sciences (UITS), Bangladesh
}

\begin{abstract}
This paper addresses the universal worthiness of actuarial sciences and works on current status and activities in the actuarial sciences landscape vis-à-vis fetches the importance of necessity of relevance in actuarial approach, capacity, applications, developments for Bangladesh, and then seeks the necessity of the systematic, framework-wise, planned measures from erudite end, academic policy makers, curriculum setter, education management, trainer and this kind of institutional bodies to realize the importance of incorporation of actuarial sciences education courses and address it's expected increasing demand for Bangladesh. This paper empathizes paying attention to take necessary and substantial measures for the inclusion of actuarial sciences courses in academic disciplines in Bangladeshi universities, through depicting some contemporary background, development scope, expected demand, importance to introducing actuarial sciences courses in academic domain to get long-term and sustainable actuarial development advantages for Econo-financial sector in Bangladesh.
\end{abstract}

Key Words: Academic, Actuarial, Insurance, Pension, Provision

\section{Introduction}

What causes writing this paper- macroeconomy is inflating, climate impact is factoring distinguishably, demographic dividend started working and so the uncertainty driven financial scope is widening and so the future expected financial positions, but the relevant skilled services are mostly absent. Hence the demand of actuarial expertise is increasing notably.

\subsection{Background to actuarial profession}

The actuarial activities in the UK and European countries, Australia, North American countries like USA, Canada, Asian countries like Japan are at great level. Also, good at some Asian countries like Singapore, Malaysia, Hong Kong, Taiwan, China, middle-east countries, Korea etc and very specifically in India and Pakistan in the south Asia. But, Bangladesh condition is still underdeveloped so far.

There is business there is uncertainty. A typical business problem might involve analyzing future financial events, especially when factoring elements play uncertain role. Actuaries are the key players of quantitative management finding ways to manage financial uncertainties in the future and hence construct analytical backbone of our society's financial security programs so that the long term financial safeguards remain in progress and emerging risk tackles through combination of strong analytical skills using mathematical and statistical tools on relevant basis, business matrices and financial aspects, and understanding of human behavior to manage current complex risks facing our society in both micro and macro level. In structural procedure actuary evaluate the likelihood of future events, designing creative ways to reduce the likelihood of undesirable events by decreasing the impact of undesirable events that do occur. The entire work is mostly model based. This kind of application is very useful to many financial industries of traditional like pension, insurance; investments, banking, healthcare etc and non-traditional as well. A single decision from actuarial ground can make a world of difference in financial herald and major financial impact for these types of industries. Apart from this, service is valuable to non-traditional sectors as well. Actuary does work on catastrophic risk and anticipate the expected economic loss at prior within acceptable level of confidence. It could be also involved understanding something like the weather analysis in the manner of catastrophic risk: assessing when and where devastating storms may hit and their associated costs, for investments or insurance. What makes difference of a actuary from other professionals like a university professor in Mathematics, or Economics, or Finance, or Statistics- actuary first Realize how businesses operate, this really set actuaries apart are their natural mathematical, economic and statistical awareness, and their ability to apply this to real business issues and have the ability to communicate these difficult topics to non-specialists in requirement basis which is very important.

These make the actuarial education is the one of the most essential educations in first world countries applied to the field of Finance, Economics, Management, research at there. 
Actuaries are consummate financial professionals in pension, insurance, business and financial economics. As long as the functional activities are concern, actuaries do work in multi-levels in a range of industries where justified financial modeling and time-to-time update underlying changes, say to become fit to set of regulatory changes, in their activities. For example, in the life office, their routine work includes to all stages in the product designing, development and pricing, risk assessment and marketing of the products, reserve calculation, dividend policy setting, expense analysis, strategic analysis for long-term from multidimensional point of views as per regulatory requirements and the subsequent changes in business obeying set of accounting standards, with the objective of business growth progresses consistently. With recent legislation in the UK leading to more private healthcare provision, insurance companies are extending their range of products to include medical insurance, critical illness and disability insurance. Besides, general insurance is a fastgrowing area for actuaries, both within insurance companies and consultancies as well as reinsurance and broking operations. General insurance includes personal insurance, such as home and motor insurance, as well as insurance for large commercial risks. Caribbean windstorms and industrial diseases like asbestosis are all examples of insurance liabilities where actuaries have been involved overall in estimating ultimate costs into an uncertain future. In the world of finance and investment, actuaries have been involved in the field of investment management for decades. Their service to stock exchange is tremendous through buying and selling assets, investment analysis and portfolio management. Many employers recognize the skills of actuaries to asset management strategically and so the intellectual contribution to the financial economics. Actuaries are becoming increasingly involved in banking top level positions for striking decision to make on finance and risk. Also in retail banking increasingly employing actuaries believing on the long-term approach from actuarial perspective can add value to the businesses. As the insurance and banking markets continue to converge, the expected demand for actuaries within banking industry continue to grow. Actuaries also do work in the province of the investment banking. An actuary's basic skills in forecasting and assessing risks are ideal for estimates the viability of a capital project financially. Last but, not the least, in Pension avenue actuary's main role is to comprehensive designing and evaluation as per regulator's requirements, vis-à-vis accounting standards, administrating, and calculation relating to obligation, scheme transformation, and scheme governance structure and advising on company pension schemes to trustees, management and sponsoring company.

In general, Actuarial science has two frontiers of academic approach through university degree in undergrad, masters and doctoral program and other is the professional degree accredited by the actuarial society or association, or institute. In both they are underpinned with mathematics. Basically, in academic vicinity the basic theoretical concepts are dealt. On the other hand professional portion is very relevant to handling through practical work based skill and pragmatic experiences along with passing due dreaded theoretical exams. There is a structure of connection between academic to professional institutes subject to the extent in the syllabus and contents and having privatization from exempting of professional examinations on the relevance and merit of individuals earning grade and score basis earned at university level, there is a set of schemes in exemptions for departments to departments and universities to universities. In professional line, fellowship, associate are the accreditations with signing authority. If anyone having academic accreditation would like to involve to the society or institute he can do it and he may apply for exemption from professional exams subject to the appropriate method of relevant policy in specific institute or society.

\subsection{Objective of the paper}

The work has been carried out with the following objectives:

i. To evaluate the existing scenario of actuarial sciences education and professional practice in Bangladesh

ii. To manifest the necessity of actuarial sciences education in Bangladesh.

iii. To instruct the timely measures to be taken by education policy makers on actuarial science education and demonstrate a sample framework to foster the actuarial study for the professional context through academic frontier aiming a long-term advantage for potential service skill sector in Bangladesh.

\subsection{Contribution of this paper}

This paper shows importance to incorporate actuarial science education course in university level curriculum in Bangladesh and hereby shows why actuarial sciences education courses are appropriate for Bangladesh with respect to long-term scope. As long as application is concern this paper plays a role of guiding for baseline foundation of actuarial science education skeleton through fixing a couple of actuarial science courses in existing relevant curriculum and the prolific starting of long term actuarial profession in Bangladesh. In advantage point of view, relevant, appropriate and integrated information with aspects are fetched in a single nut-shell aiming to realize the time-revolutionary increasing demand of actuarial sciences education.

\section{Methodology}


Required information has been collected from both primary and secondary sources along with data and information from a series of domestic and international actuarial seminar, conferences attended in last seven years and the experience from the practice in actuarial landscape in last three years. Primary data was collected from different relevant offices including the Actuarial Society of Bangladesh (ASB), Bangladesh Insurance Academy (BIA), Actuarial firms, the Insurance Development and Regulatory Authority (IDRA). The sources of secondary information include relevant office circulars, announcements, books, journals, magazines, newspapers and so on from different associations; societies, institutes, and actuarial body's website for say the International Actuarial Association (IAA), the Institute and Faculty of Actuaries, UK, Institute of Actuaries of India (IAI), India, Society of Actuaries (SoA), USA, Bangladesh Bank (BB), Bangladesh Bureau of Statistics (BBS) etc.

\section{Body}

The body comprises seven relevant subheads of first one on economic status of Bangladesh, demographic orientation, climate condition of Bangladesh thereby the worthiness of incorporation of actuarial education, current actuarial status of Bangladesh, possibility of playing prominent role of academic part actively in Bangladesh and proposal for actuarial sciences development at this primary stage in Bangladesh.

\subsection{Bangladesh - Economic status}

There are a range of factors indicate the consistent growth of economy of Bangladesh out of which only budget volume, Gross Domestic Product (GDP), progress of financial institutions, inflation, bank rate factors are taken into discussion table.

As long as national annual total budget is concern, in FY 2008-2009, FY 2009-2010, FY 2010-2011, FY 2011-2012, FY 2012-2013 and FY 2013-14 the size is BDT 893,160 million; 1,015,210 million; 1,282,570 million; 1,612,130 million; 1,917,380 million; and 2,224,910 million respectively. This indicates the gradual spreading of macroeconomics health in the light of budget is remarkable for Bangladesh as turnover in the economy is climbing up. The trends of GDP of Bangladesh in the last five years from 2009 to 2013 are 89.37, $100.36,111.91,116.03,129.86$ billion US dollar each year respectively with consistent growth which indicates an impressive track record for growth and development heading to become a middle-income country near future. Moreover, bank rate has been steady at $5.00 \%$ for the years and the monthly average inflation is just $7.22 \%$ in Bangladesh.

It's macroeconomic components getting enlarged and leaving scope for employment opportunities. In industry-wise view now it's life insurance company size is 31 including state-owned and foreign subsidiary companies and 46 domestic general insurance companies including state-owned companies, 58 banks including state-owned, specialized, private and foreign commercial, also 33 non-banking financial organizations, 2 stock exchanges have been functioning actively to vibrant economy of Bangladesh. The financial activities experiencing more mobility, the nine new banks coming into operation besides newly opened 13 life and 2 general insurance companies in the economy in last 3 years. Hence, the uncertainty-driven financial activities lump and coming to the front line in the priority list gradually. Therefore, the actuarial worker demand would be a noting position in the service market.

Considering all these into the single frame with respect to actuarial tools application and demand of actuarial approach for traditional work scope at actuarial desks in both kinds of insurance companies, risk management and investment departments in banks, brokerage houses' portfolio and asset management in context to capital market performance, pension and employees' benefit industry with a long-term planning, it is essential for actuarial human resource development.

\subsection{Bangladesh - Demographic dividend}

Taking attention to the demographic picture of the country, the country has the demographic dividend stage for last 4 years. The size of young society of Bangladesh is leading the entire demographic orientation now. So, the contribution from this youth (like South Korea) is essential for future developments. In course of time this community will turn into aged society (like Japan now) and there should be provisioning from now for this aged society as at their old their cumulative liabilities will impact the entire future economy of Bangladesh.

\subsection{Bangladesh - Climate status}

Bangladesh is one of the climate vulnerable countries over the globe due to its geo-location. A significant part of the land of country is prone to flood, earthquake, and some areas is turning into draught. Therefore, being a climate vulnerable Bangladesh require specialist in catastrophic risk professionals like actuary to estimate the financial back-up to face the challenges arose due to uncertainties driven by the climate changes. 


\subsection{Why Actuarial education is necessary in Bangladesh?}

Fields of actuarial activities includes traditional and non-traditional capacities. In relevant to Bangladesh the opportunity in the traditional part is vivid and that includes life insurance industry, non-life insurance industry, micro-insurance operating NGOs, pension industry, Risk management in banking and capital market. At where the key factors in the actuarial perspective are determining the value of expected future financial provision due to uncertainty at both life and properties insurance, expected defined pension and social security, catastrophic driven financial risk, old society impact etc. These would play deadly role to drive Bangladesh being prone to long-term financial hazards. For a sustainable economic and financial preparation and provisions for expected future financial outcomes actuarial application could way out Bangladesh from financial jeopardizing.

\subsection{Actuarial Status in Bangladesh}

Actuarial Science and its courses were hardly known to mass people in business industry even to university faculties in Bangladesh. Before the establishment of Actuarial Society of Bangladesh (ASB) in 2007 there was a professional examination centre conducted by the Institute of Actuaries of India (former Actuarial Society of India) in Dhaka and 2 to 3 students used to write examinations but not at regular basis. After formation of ASB another professional examination centre of the UK Institute and Faculty of Actuaries (former Institute of Actuaries, England) started working by the assistance of ASB. ASB conducted many seminars to collect local talents to attach with actuarial sciences, conducted actuarial coaching, problem solving classes, group discussion etc. The latest is on average there are 20 students writes actuarial exams in each semester both Indian and UK exams. And the pass rate is quite good. There is a lifting in actuarial professional activities and a transition time for Bangladesh. But, the role of Actuarial Society of Bangladesh (ASB) is not that sufficient proportion to the growth due to some of its unavoidable limitations. There was a role also from the Insurance Development and Regulatory Authority (IDRA) in 2 years back through publishing circular and announcement to mandatorily opening Actuarial Desk and appointing actuarial part qualified students. No that foremost role from IDRA in this regard thereafter.

The most acceptable degree to the employers in business, commercial and financial enterprises is BBA and MBA of business discipline, some other degrees from the discipline of Economics, Statistics, are also appreciated profusely. These degree holders are serving the most business, commerce and financial sector in Bangladesh. There are 3 to 4 universities including Bangladesh University of Business and Technology (BUBT), Institute of Statistical Research and Training (ISRT) and Department of Statistics at Dhaka University (DU) and Department of Statistics at Jahangirnagar University are conducting 1-2 actuarial courses in master's level so far.

\subsection{Bangladesh - Why academic section emphasized first?}

Why to pay attention in academic side first? This is apparent that it is comparatively easier to fulfill the aim in this line as there are 74 private and 34 public universities in Bangladesh. Albeit Pass rate in professional exams of UK institute, Indian Institute is satisfactory but becoming a qualified actuary it requires fulfillment of other requirements to the full such as work base skill etc besides passing all due written dreaded exams. But achieving work base skill is so far difficult to gain due to location disadvantage residing in Bangladesh as the size of total signatory actuary in Bangladesh is only four and most of them are from aged society. Also a qualified actuary hardly get engaged in back office work so actuarial peoples from academic herald could serve the back office as hands of qualified actuaries. Besides, an actuarial environment would likely to be created massively through academic introduction.

\subsection{Proposal for actuarial development in Bangladesh - At primary stage}

First of all it is needed to introduce the relevant fundamental Mathematics, Statistics, Economics and their concepts in the syllabus. Then, to incorporation actuarial sciences course relevant to both kinds of insurance of long-term and short-term issues and its background, purposes, numerical derivation methods, limitation of use etc in the syllabus; also, requirements, purpose of assessments, objective of work scope etc along with actuarial risk management itineraries in relation to pension and employees' benefit scheme and funds calculation are to set in the syllabus for the time being. In parallel, the assistance from professionals including part qualified actuaries on need and relevant basis could be sought for broad spectrum of analyzing practical scenario and case study analysis including relevant standards, professionalism, and ethics and their sensible practice and applications.

Some actuarial courses to be incorporated in the university level either in bachelor or masters to figure out actuarial issues. During setting syllabus and curriculum attention is needed to pay on what topics to be included relevant to Bangladesh perspective and international standardized syllabus. Planning for introducing 34 preliminary actuarial courses in undergrad level consisting the contents of professional exams syllabus which 
would pay off to professional exam writer. Continuing development process might be incorporating for those preliminary courses and starting masters program in actuarial science and management thereafter; further, starting bachelor program in the same subject. The professional involving will be distinguishably raised through academic performance.

One of the major limitations of introducing the actuarial courses in different disciplines is shortage of resource persons. This problem can be solved through working with Actuarial Society of Bangladesh (ASB) together as it conducts actuarial classes with the help of International Actuarial Association (IAA)'s wing Actuaries Without Boarder (AWB) with foreign resource personnel. The university could ask help from ASB for arsenals of actuarial resource capacities. Besides, there are, in total, 2 fellow level and 2 associate level and more than 20 part qualified level actuaries with good actuarial practice and consultancy track annals in Bangladesh who could be engaged in university level actuarial course delivering, management, administrating etc for starting couple of years. The part qualified actuarial personnel who has good record of long-length of actuarial professional works inside and outside of Bangladesh could pay off as resource professionals in parallel to fellows and associate actuaries, but they are not expected as good as that of signatories.

\section{Conclusion}

This paper is indicative in the sense it approaches the paramount necessity of actuarial knowledge for Bangladesh and plays a great role as instructive in the sense it pointed out the measures of education policy makers to pay attention into upcoming actuarial demands. In nut-shell, the possible assistance could be found through this paper in two ways as indicative and instructive for well-timed enriching the academic curriculum at university level and to open a set-up for long-term intellectual expertise.

There might some information shortage during preparing this paper may lead couple of changes in the inference literatures in the subhead title of "3.7 Proposal for actuarial development in Bangladesh: At primary stage" as the subtitle is written based on the capacity to access for the relevant and complete information.

\section{References}

[1]. The Documents from the Actuarial Society of Bangladesh (ASB), Bangladesh

[2]. The website information from University Grants Commission (UGC) of Bangladesh

[3]. The information from BBS (Bangladesh Bureau of Statistics), Bangladesh

[4]. The website information from the Bangladesh Bank (BB), Bangladesh

[5]. The website information of the Insurance Development and Regulatory Authority (IDRA), Bangladesh

[6]. The documents from the International Actuarial Association (IAA)

[7]. The website information, magazine, articles from the Institute and Faculty of Actuaries (IFoA), UK

[8]. The website information, magazine, articles from the Institute of Actuaries of India (IAI), India

[9]. The website information from the Society of Actuaries (SoA), USA 